\title{
Standards of Medical Care in Diabetes-2016 Abridged for Primary Care Providers
}

American Diabetes Association

This is an abridged version of the American Diabetes Association Position Statement: Standards of Medical Care in Diabetes-2016. Diabetes Care 2016;39(Suppl. 1):S1-S112.

The complete 2016 Standards supplement, including all supporting references, is available at http://diabetesjournals.org/ content/39/Supplement_1.toc.

DOI: $10.2337 /$ diaclin.34.1.3

(C)2016 by the American Diabetes Association. Readers may use this article as long as the work is properly cited, the use is educational and not for profit, and the work is not altered. See http:// creativecommons.org/licenses/by-nc-nd/3.0 for details.

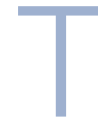

he American Diabetes Association's (ADA's) Standards of Medical Care in Diabetes is updated and published annually in a supplement to the January issue of Diabetes Care. Formerly called Clinical Practice Recommendations, the Standards includes the most current evidence-based recommendations for diagnosing and treating adults and children with all forms of diabetes. ADA's grading system uses A, B, C, or E to show the evidence level that supports each recommendation.

- A-Clear evidence from wellconducted, generalizable randomized controlled trials that are adequately powered

- B-Supportive evidence from well-conducted cohort studies

- C-Supportive evidence from poorly controlled or uncontrolled studies

- E-Expert consensus or clinical experience

This is an abridged version of the current Standards containing the evidence-based recommendations most pertinent to primary care. The tables and figures have been renumbered from the original document to match this version. The complete 2016 Standards of Care document, including all supporting references, is available at professional.diabetes. org/standards.

\section{STRATEGIES FOR IMPROVING CARE}

\section{Recommendations}

- A patient-centered communication style that incorporates patient preferences, assesses literacy and numeracy, and addresses cultural barriers to care should be used. B

- Care should be aligned with components of the Chronic Care Model (CCM) to ensure productive interactions between a prepared, proactive practice team and an informed, activated patient. A

- When feasible, care systems should support team-based care, community involvement, patient registries, and decision support tools to meet patient needs. B

\section{Diabetes Care Concepts}

- Patient-centeredness. Patients with diabetes are at a greatly increased risk of cardiovascular disease (CVD). A patient-centered approach should include a comprehensive plan to reduce cardiovascular risk by addressing blood pressure and lipid control, smoking prevention and cessation, weight management, physical activity, and healthy lifestyle choices.

- Diabetes across the life span. The incidence of type 2 diabetes is increasing in children and young adults. Patients with type 1 diabetes or type 2 diabetes are living well into older age. Coordination must improve between clinical teams as patients transition through different stages of life. 


\section{Care Delivery Systems}

\section{Chronic Care Model}

The CCM has been shown to be an effective framework for improving the quality of diabetes care. Collaborative, multidisciplinary teams are best equipped to provide care for people with chronic conditions such as diabetes. The CCM also facilitates patients' self-management.

Key Objectives

1. Optimize provider and team behavior. The care team should prioritize timely and appropriate intensification of lifestyle and/or pharmacological therapy for patients who have not achieved beneficial levels of glucose, blood pressure, or lipid control.

2. Support patient behavior change. High-quality diabetes self-management education (DSME) has been shown to improve patient self-management, satisfaction, and glucose control.

3. Change the care system. Optimal diabetes management requires an organized, systematic approach and involves a coordinated team of dedicated health care professionals.

\section{When Treatment Goals Are Not Met}

Several strategies have been shown to improve patient outcomes. Providers should focus on treatment intensification, which has been associated with improvement in $\mathrm{A} 1 \mathrm{C}$, hypertension, and hyperlipidemia.

Patient adherence should be addressed. Barriers may include patient factors (e.g., remembering to obtain or take medications, fears, depression, and health beliefs), medication factors (e.g., complexity, multiple daily dosing, cost, and side effects), and system factors (e.g., inadequate follow-up and support). Simplifying a complex treatment regimen may improve adherence.

TABLE 1. Criteria for the Diagnosis of Diabetes

$F P G \geq 126 \mathrm{mg} / \mathrm{dL}(7.0 \mathrm{mmol} / \mathrm{L})$.

Fasting is defined as no caloric intake for at least $8 \mathrm{~h}$. *

\section{OR}

2-h plasma glucose $\geq 200 \mathrm{mg} / \mathrm{dL}$ (11.1 $\mathrm{mmol} / \mathrm{L})$ during an OGTT.

The test should be performed as described by the World Health

Organization, using a glucose load containing the equivalent of $75 \mathrm{~g}$ anhydrous glucose dissolved in water.*

OR

$\mathrm{A} 1 \mathrm{C} \geq 6.5 \%$ (48 $\mathrm{mmol} / \mathrm{mol})$. The test should be performed in a laboratory using a method that is NGSP certified and standardized to the DCCT assay.*

OR

In a patient with classic symptoms of hyperglycemia or hyperglycemic crisis, a random plasma glucose $\geq 200 \mathrm{mg} / \mathrm{dL}(11.1 \mathrm{mmol} / \mathrm{L})$.* $^{* *}$

*In the absence of unequivocal hyperglycemia, results should be confirmed by repeat testing.

** Only diagnostic in a patient with classic symptoms of hyperglycemia or hyperglycemic crisis.

\section{Tailoring Treatment to Vulnerable Populations}

\section{Ethnic/Cultural/Sex/}

Socioeconomic Differences and Disparities

Ethnic, cultural, religious, and sex differences and socioeconomic status may affect diabetes prevalence and outcomes. Diabetes management requires individualized, patient-centered, and culturally appropriate strategies. Strong social support leads to improved clinical outcomes, reduced psychosocial symptomatology, and adoption of healthier lifestyles. Structured interventions that are tailored to ethnic populations and integrate culture, language, religion, and literacy skills have a positive impact on patient outcomes.

\section{Food Insecurity}

\section{Recommendations}

- Providers should carefully evaluate hyperglycemia and hypoglycemia in the context of food insecurity (FI) and propose solutions accordingly. A

- Providers should recognize that homelessness, poor literacy, and poor numeracy often occur with food insecurity, and appropriate resources should be made available for patients with diabetes. A
FI is the unreliable availability of nutritious food and the inability to consistently obtain food without resorting to socially unacceptable practices. Hyperglycemia and hypoglycemia are more common in those with diabetes and FI.

\section{Cognitive Dysfunction}

\section{Recommendations}

- In individuals with poor cognitive function or severe hypoglycemia, glycemic therapy should be tailored to avoid significant hypoglycemia. C

- In individuals with diabetes at high cardiovascular risk, the cardiovascular benefits of statin therapy outweigh the risk of cognitive dysfunction. A

- If a second-generation antipsychotic medication is prescribed, changes in weight, glycemic control, and cholesterol levels should be carefully monitored and the treatment regimen reassessed. C

Dementia is the most severe form of cognitive dysfunction. In those with type 2 diabetes, both degree and duration of hyperglycemia are related to dementia. More rapid cognitive decline is associated with increased $\mathrm{A} 1 \mathrm{C}$ and longer duration of diabetes. 


\section{TABLE 2. Criteria for Testing for Diabetes or Prediabetes in Asymptomatic Adults}

1. Testing should be considered in all adults who are overweight (BMI $\geq 25 \mathrm{~kg} / \mathrm{m}^{2}$ or $\geq 23 \mathrm{~kg} / \mathrm{m}^{2}$ in Asian Americans) and have additional risk factors:

- Physical inactivity

- First-degree relative with diabetes

- High-risk race/ethnicity (e.g., African American, Latino, Native American, Asian American, Pacific Islander)

- Women who delivered a baby weighing $>9 \mathrm{lb}$ or were diagnosed with GDM

- Hypertension ( $\geq 140 / 90 \mathrm{mmHg}$ or on therapy for hypertension)

- HDL cholesterol level $<35 \mathrm{mg} / \mathrm{dL}(0.90 \mathrm{mmol} / \mathrm{L})$ and/or a triglyceride level $>250 \mathrm{mg} / \mathrm{dL}(2.82 \mathrm{mmol} / \mathrm{L})$

- Women with polycystic ovary syndrome

- $\mathrm{A} 1 \mathrm{C} \geq 5.7 \%$ ( $39 \mathrm{mmol} / \mathrm{mol})$, IGT, or IFG on previous testing

- Other clinical conditions associated with insulin resistance (e.g., severe obesity, acanthosis nigricans)

- History of CVD

2. For all patients, testing should begin at age 45 years.

3. If results are normal, testing should be repeated at a minimum of 3-year intervals, with consideration of more frequent testing depending on initial results (e.g., those with prediabetes should be tested yearly) and risk status.

IFG, impaired fasting glucose; IGT, impaired glucose tolerance.

In type 2 diabetes, severe hypoglycemia is associated with reduced cognitive function, and those with poor cognitive function have more severe hypoglycemia. Data do not support an adverse effect of statins on cognition.

\section{Mental Illness}

The prevalence of type 2 diabetes is two to three times higher in people with schizophrenia, bipolar disorder, or schizoaffective disorder than in the general population. Diabetes medications are effective regardless of mental health status. Treatments for depression are effective in patients with diabetes, and treating depression may improve short-term glycemic control. Awareness of an individual's medication profile, especially if the individual takes psychotropic medications, is key to effective management.

\section{CLASSIFICATION AND DIAGNOSIS OF DIABETES}

Diabetes can be classified into the following general categories:

1. Type 1 diabetes (due to $\beta$-cell destruction, usually leading to absolute insulin deficiency)

2. Type 2 diabetes (due to a progressive insulin secretory defect on the background of insulin resistance)

3. Gestational diabetes mellitus (GDM) (diabetes diagnosed in the second or third trimester of pregnancy that is not clearly overt diabetes)

4. Specific types of diabetes due to other causes such as monogenic diabetes syndromes (e.g., neonatal diabetes or maturity-onset diabetes of the young [MODY]), diseases of the exocrine pancreas (e.g., cystic fibrosis), or drug- or chemical-induced diabetes (e.g., as in the treatment of HIV/AIDS or after organ transplantation)

\section{Diagnostic Tests for Diabetes}

Diabetes may be diagnosed based on plasma glucose criteria-either the fasting plasma glucose (FPG) or the 2-h plasma glucose value after a 75 -g oral glucose tolerance test (OGTT) or A1C criteria (Table 1). The same tests are used to screen for and diagnose diabetes and to detect individuals with prediabetes (Table 2).

\section{Type 2 Diabetes and Prediabetes}

\section{Recommendations}

- Testing to detect type 2 diabetes in asymptomatic people should be considered in adults of any age who are overweight or obese (BMI $\geq 25 \mathrm{~kg} / \mathrm{m}^{2}$ or $\geq 23 \mathrm{~kg} / \mathrm{m}^{2}$ in Asian Americans) and who have one or more additional risk factors for diabetes. B
- For all patients, testing should begin at age 45 years. B

- If tests are normal, repeat testing carried out at a minimum of 3-year intervals is reasonable. C

- In patients with prediabetes or diabetes, identify and, if appropriate, treat other CVD risk factors. B

- Screen women with GDM for persistent diabetes at 6-12 weeks postpartum using the OGTT and clinically appropriate nonpregnancy diagnostic criteria. E

- Testing to detect prediabetes and type 2 diabetes should be considered in children and adolescents who are overweight or obese and who have two or more additional risk factors for diabetes. $\mathrm{E}$

The modified recommendations of the ADA consensus report "Type 2 Diabetes in Children and Adolescents" are summarized in Table 3.

\section{FOUNDATIONS OF CARE AND COMPREHENSIVE MEDICAL EVALUATION}

\section{Foundations of Care}

It is necessary to take into account all aspects of a patient's life circumstances. A team approach to care and a comprehensive clinical assessment should incorporate behavioral, di- 


\section{TABLE 3. Testing for Type 2 Diabetes or Prediabetes in Asymptomatic Children*}

Criteria

- Overweight (BMI $>85$ th percentile for age and sex, weight for height $>85$ th percentile, or weight $>120 \%$ of ideal for height)

Plus any two of the following risk factors:

- Family history of type 2 diabetes in first- or second-degree relative

- Race/ethnicity (Native American, African American, Latino, Asian American, Pacific Islander)

- Signs of insulin resistance or conditions associated with insulin resistance (acanthosis nigricans, hypertension, dyslipidemia, polycystic ovary syndrome, or small-for-gestational-age birth weight)

- Maternal history of diabetes or GDM during the child's gestation

Age of initiation: age 10 years or at onset of puberty, if puberty occurs at a younger age

Frequency: every 3 years

*People aged $\leq 18$ years.

TABLE 4. Components of the Comprehensive Diabetes Medical Evaluation

\section{Medical history}

- Age and characteristics of onset of diabetes (e.g., DKA, asymptomatic laboratory finding)

- Eating patterns, nutritional status, weight history, and physical activity habits; nutrition education and behavioral support history and needs

- Presence of common comorbidities, psychosocial problems, and dental disease

- Screen for depression using PHQ-2 (PHQ-9 if PHQ-2 positive) or EPDS

- Screen for DD using DDS or PAID-1

- History of smoking, alcohol consumption, and substance use

- Diabetes education, self-management, and support history and needs

- Review of previous treatment regimens and response to therapy (A1C records)

- Results of glucose monitoring and patient's use of data

- DKA frequency, severity, and cause

- Hypoglycemia episodes, awareness, and frequency and causes

- History of increased blood pressure, increased lipids, and tobacco use

- Microvascular complications: retinopathy, nephropathy, and neuropathy (sensory, including history of foot lesions; autonomic, including sexual dysfunction and gastroparesis)

- Macrovascular complications: coronary heart disease, cerebrovascular disease, and peripheral arterial disease

\section{Physical examination}

- Height, weight, and BMI; growth and pubertal development in children and adolescents

- Blood pressure determination, including orthostatic measurements when indicated

- Fundoscopic examination

- Thyroid palpation

- Skin examination (e.g., for acanthosis nigricans, insulin injection, or infusion set insertion sites)

- Comprehensive foot examination

- Inspection

- Palpation of dorsalis pedis and posterior tibial pulses

- Presence/absence of patellar and Achilles reflexes

- Determination of proprioception, vibration, and monofilament sensation

\section{Laboratory evaluation}

- $\mathrm{A} 1 \mathrm{C}$, if results not available within the past 3 months

- If not performed/available within the past year

- Fasting lipid profile, including total, LDL, and HDL cholesterol and triglycerides, as needed

- Liver function tests

- Spot urinary albumin-to-creatinine ratio

- Serum creatinine and estimated glomerular filtration rate

o Thyroid-stimulating hormone in patients with type 1 diabetes or dyslipidemia or women aged $>50$ years

DD, diabetes distress; DDS, Diabetes Distress Scale; DKA, diabetic ketoacidosis; EPDS, Edinburgh Postnatal

Depression Scale; PAID, Problem Areas in Diabetes; PHQ, Patient Health Questionnaire. 
etary, lifestyle, and pharmaceutical intervention to manage this chronic condition (Table 4). Using the CCM may help improve the quality of diabetes care.

\section{Diabetes Self-Management Education and Support}

\section{Recommendations}

- In accordance with the National Standards for Diabetes SelfManagement Education and Support, all people with diabetes should participate in DSME to facilitate the knowledge, skills, and abilities necessary for diabetes self-care and diabetes self-management support (DSMS) to assist with implementing and sustaining skills and behaviors needed for ongoing self-management, both at diagnosis and as needed thereafter. B

- Effective self-management, improved clinical outcomes, health status, and quality of life are key outcomes of DSME/S and should be measured and monitored as part of care. C

- DSME/S should be patient-centered, respectful, and responsive to individual patient preferences, needs, and values, which should guide clinical decisions. A

- DSME/S programs should have the necessary elements in their curricula that are needed to prevent the onset of diabetes. DSME/S programs should therefore tailor their content specifically when prevention of diabetes is the desired goal. B

- Because DSME/S can result in cost savings and improved outcomes B, they should be adequately reimbursed by third-party payers. E

There are four critical time points for DSME/S delivery: at diagnosis; annually for assessment of education, nutrition, and emotional needs; when new complicating factors arise that influence self-management; and when transitions in care occur.

\section{Medical Nutrition Therapy}

There is no one-size-fits-all eating pattern for individuals with diabetes. There are basic guidelines that can support the team in engaging the patient in more healthful eating patterns (Table 5).

The goals of medical nutrition therapy (MNT) are to promote and support healthful eating patterns, emphasizing a variety of nutrient-dense foods in appropriate portion sizes to achieve/maintain body weight goals; attain glycemic, lipid, and blood pressure goals; and delay/prevent complications of diabetes. MNT addresses individual nutrition needs based on personal and cultural preferences, health literacy, and access to healthful foods. It maintains the pleasure of eating by providing nonjudgmental messages about food choices and offers practical tools for developing healthy patterns.

All individuals should be encouraged to replace refined carbohydrates and added sugars with whole grains, legumes, vegetables, and fruit. Individuals who take mealtime insulin should be offered intensive education on coupling insulin administration with carbohydrate intake.

Weight loss is discussed in more detail below.

\section{Physical Activity}

\section{Recommendations}

- Children with diabetes or prediabetes should be encouraged to engage in at least $60 \mathrm{~min}$ of physical activity each day. B

- Adults with diabetes should be advised to perform at least 150 $\mathrm{min} /$ week of moderate-intensity aerobic physical activity (50-70\% maximum heart rate), spread over at least 3 days/week with no more than 2 consecutive days without exercise. $\mathrm{A}$
- All individuals, including those with diabetes, should be encouraged to reduce sedentary time, particularly by breaking up extended amounts of time $(>90$ min) spent sitting. B

- In the absence of contraindications, adults with type 2 diabetes should be encouraged to perform resistance training at least twice per week. A

Physical activity is a general term that includes all movement that increases energy use and is an important part of the diabetes management plan. Exercise is a more specific form of physical activity that is structured and designed to improve physical fitness.

There is no routine pre-exercise testing recommended. However, providers should assess patients for conditions that might contraindicate certain types of exercise or predispose to injury and customize the exercise regimen to the individual's needs.

\section{Smoking Cessation: Tobacco and e-Cigarettes}

\section{Recommendations}

- Advise all patients not to use cigarettes, other tobacco products, or e-cigarettes. A

- Include smoking cessation counseling and other forms of treatment as a routine component of diabetes care. $\mathrm{B}$

\section{Immunizations}

\section{Recommendations}

- Provide routine vaccinations for children and adults with diabetes as for the general population according to age-related recommendations. C

- Administer hepatitis B vaccine to unvaccinated adults with diabetes who are aged 19-59 years. C

- Consider administering hepatitis $B$ vaccine to unvaccinated adults with diabetes who are aged $\geq 60$ years. C 
TABLE 5. Nutrition Therapy Recommendations

\begin{tabular}{|c|c|c|}
\hline Topic & Recommendations & $\begin{array}{l}\text { Evidence } \\
\text { rating }\end{array}$ \\
\hline \multirow{5}{*}{$\begin{array}{l}\text { Effectiveness } \\
\text { of nutrition } \\
\text { therapy }\end{array}$} & $\begin{array}{l}\text { - An individualized MNT program, preferably provided by a registered dietitian, is rec- } \\
\text { ommended for all people with type } 1 \text { or type } 2 \text { diabetes. }\end{array}$ & A \\
\hline & $\begin{array}{l}\text { - For people with type } 1 \text { diabetes or those with type } 2 \text { diabetes who are prescribed a } \\
\text { flexible insulin therapy program, education on how to use carbohydrate counting or } \\
\text { estimation to determine mealtime insulin dosing can improve glycemic control. }\end{array}$ & A \\
\hline & $\begin{array}{l}\text { - For individuals whose daily insulin dosing is fixed, having a consistent pattern of } \\
\text { carbohydrate intake with respect to time and amount can result in improved glycemic } \\
\text { control and a reduced risk of hypoglycemia. }\end{array}$ & B \\
\hline & $\begin{array}{l}\text { - A simple and effective approach to glycemia and weight management emphasizing } \\
\text { healthy food choices and portion control may be more helpful for those with type } 2 \\
\text { diabetes who are not taking insulin, who have limited health literacy or numeracy, and } \\
\text { who are elderly and prone to hypoglycemia. }\end{array}$ & C \\
\hline & $\begin{array}{l}\text { - Because diabetes nutrition therapy can result in cost savings B and improved out- } \\
\text { comes (e.g., A1C reduction) A, MNT should be adequately reimbursed by insurance } \\
\text { and other payers. E }\end{array}$ & $B, A, E$ \\
\hline $\begin{array}{l}\text { Energy } \\
\text { balance }\end{array}$ & $\begin{array}{l}\text { - Modest weight loss achievable by the combination of lifestyle modification and the } \\
\text { reduction of energy intake benefits overweight or obese adults with type } 2 \text { diabetes } \\
\text { and also those at risk for diabetes. Interventional programs to facilitate this process } \\
\text { are recommended. }\end{array}$ & A \\
\hline \multirow{3}{*}{$\begin{array}{l}\text { Eating } \\
\text { patterns and } \\
\text { macronutrient } \\
\text { distribution }\end{array}$} & $\begin{array}{l}\text { - As there is no single ideal dietary distribution of calories among carbohydrates, fats, } \\
\text { and proteins for people with diabetes, macronutrient distribution should be individual- } \\
\text { ized while keeping total calorie and metabolic goals in mind. }\end{array}$ & $E$ \\
\hline & $\begin{array}{l}\text { - Carbohydrate intake from whole grains, vegetables, fruits, legumes, and dairy prod- } \\
\text { ucts, with an emphasis on foods higher in fiber and lower in glycemic load, should be } \\
\text { advised over other sources, especially those containing sugars. }\end{array}$ & B \\
\hline & $\begin{array}{l}\text { - People with diabetes and those at risk should avoid sugar-sweetened beverages in } \\
\text { order to control weight and reduce their risk for CVD and fatty liver B and should min- } \\
\text { imize the consumption of sucrose-containing foods that have the capacity to displace } \\
\text { healthier, more nutrient-dense food choices. A }\end{array}$ & $B, A$ \\
\hline Protein & $\begin{array}{l}\text { - In individuals with type } 2 \text { diabetes, ingested protein appears to increase insulin re- } \\
\text { sponse without increasing plasma glucose concentrations. Therefore, carbohydrate } \\
\text { sources high in protein should not be used to treat or prevent hypoglycemia. }\end{array}$ & B \\
\hline \multirow[t]{2}{*}{ Dietary fat } & $\begin{array}{l}\text { - Whereas data on the ideal total dietary fat content for people with diabetes are in- } \\
\text { conclusive, an eating plan emphasizing elements of a Mediterranean-style diet rich in } \\
\text { monounsaturated fats may improve glucose metabolism and lower CVD risk and can } \\
\text { be an effective alternative to a diet low in total fat but relatively high in carbohydrates. }\end{array}$ & B \\
\hline & $\begin{array}{l}\text { - Eating foods rich in long-chain omega-3 fatty acids, such as fatty fish (EPA and DHA) } \\
\text { and nuts and seeds (ALA), is recommended to prevent or treat CVD B; however, evi- } \\
\text { dence does not support a beneficial role for omega-3 dietary supplements. A }\end{array}$ & $\mathrm{B}, \mathrm{A}$ \\
\hline $\begin{array}{l}\text { Micronutrients } \\
\text { and herbal } \\
\text { supplements }\end{array}$ & $\begin{array}{l}\text { - There is no clear evidence that dietary supplementation with vitamins, minerals, herbs, } \\
\text { or spices can improve diabetes, and there may be safety concerns regarding the long- } \\
\text { term use of antioxidant supplements such as vitamins E and C and carotene. }\end{array}$ & C \\
\hline \multirow[t]{2}{*}{ Alcohol } & $\begin{array}{l}\text { - Adults with diabetes who drink alcohol should do so in moderation (no more than one } \\
\text { drink per day for adult women and no more than two drinks per day for adult men). }\end{array}$ & C \\
\hline & $\begin{array}{l}\text { - Alcohol consumption may place people with diabetes at increased risk for delayed } \\
\text { hypoglycemia, especially if taking insulin or insulin secretagogues. Education and } \\
\text { awareness regarding the recognition and management of delayed hypoglycemia are } \\
\text { warranted. }\end{array}$ & B \\
\hline Sodium & $\begin{array}{l}\text { - As for the general population, people with diabetes should limit sodium consumption } \\
\text { to } \leq 2,300 \mathrm{mg} / \text { day, although further restriction may be indicated for those with both } \\
\text { diabetes and hypertension. }\end{array}$ & B \\
\hline
\end{tabular}




\section{Psychosocial Issues}

\section{Recommendations}

- The patient's psychological and social situation should be addressed in the medical management of diabetes. B

- Psychosocial screening and follow-up may include, but are not limited to, attitudes about the illness, expectations for medical management and outcomes, affect/mood, general and diabetes-related quality of life, resources (financial, social, and emotional), and psychiatric history. $\mathrm{E}$

- Routinely screen for psychosocial problems such as depression, diabetes-related distress, anxiety, eating disorders, and cognitive impairment. B

- Older adults (aged $\geq 65$ years of age) with diabetes should be considered for evaluation of cognitive function, depression screening, and treatment. B

- Patients with comorbid diabetes and depression should receive a stepwise collaborative care approach for the management of depression. A

Key opportunities for screening occur at multiple times during the management of diabetes: when medical status changes (e.g., at the end of the honeymoon period), when the need for intensified treatment is evident, and when complications are discovered. Optimizing the patient-provider relationship as a foundation may increase the likelihood of the patient accepting referral for other services.

\section{Comprehensive Medical Evaluation}

\section{Recommendations}

A complete medical evaluation should be performed at the initial visit to:

- Confirm the diagnosis and classify diabetes. B

- Detect diabetes complications and potential comorbid conditions. E
- Review previous treatment and risk factor control in patients with established diabetes. E

- Begin patient engagement in the formulation of a care management plan. B

- Develop a plan for continuing care. B

\section{PREVENTION OR DELAY OF TYPE 2 DIABETES}

\section{Recommendations}

- Patients with prediabetes should be referred to an intensive diet and physical activity behavioral counseling program adhering to the tenets of the Diabetes Prevention Program (DPP) targeting loss of $7 \%$ of body weight and should increase their moderate physical activity (such as brisk walking) to at least $150 \mathrm{~min} /$ week. A

- Metformin therapy for prevention of type 2 diabetes should be considered in those with prediabetes, especially in those with a BMI $>35$ $\mathrm{kg} / \mathrm{m}^{2}$, those aged $<60$ years, and women with prior GDM. A

- At least annual monitoring for the development of diabetes in those with prediabetes is suggested. E

- Screening for and treatment of modifiable risk factors for CVD is suggested. $\mathbf{B}$

Intensive lifestyle modification programs have been shown to be very effective $(-58 \%$ risk reduction after 3 years).

In addition, pharmacological agents such as metformin, $\alpha$-glucosidase inhibitors, orlistat, and thiazolidinediones have been shown to decrease incident diabetes to various degrees. Metformin has demonstrated long-term safety as pharmacological therapy for diabetes prevention.

\section{GLYCEMIC TARGETS}

\section{Assessment of Glycemic Control}

Recommendation

- Patients on multiple-dose insulin or insulin pump therapy should perform self-monitoring of blood glucose (SMBG) before meals and snacks, at bedtime, before exercise, when they suspect low blood glucose, after treating low blood glucose until they are normoglycemic, and before critical tasks such as driving. $\mathrm{B}$

SMBG frequency and timing should be dictated by the patient's specific needs and goals. SMBG is especially important for patients treated with insulin to monitor for and prevent asymptomatic hypoglycemia and hyperglycemia. For patients on nonintensive insulin regimens such as those with type 2 diabetes using basal insulin, when to prescribe SMBG and at what testing frequency are less established.

SMBG allows patients to evaluate their individual response to therapy and assess whether glycemic targets are being achieved. Results of SMBG can be useful in preventing hypoglycemia and adjusting medications (particularly prandial insulin doses), MNT, and physical activity. Evidence also supports a correlation between SMBG frequency and lower A1C.

SMBG accuracy is instrumentand user-dependent. Evaluate each patient's monitoring technique, both initially and at regular intervals thereafter. The ongoing need for and frequency of SMBG should be reevaluated at each routine visit.

\section{A1C Testing}

\section{Recommendations}

- Perform the A1C test at least two times per year in patients who are meeting treatment goals (and who have stable glycemic control). E

- Perform the A1C test quarterly in patients whose therapy has changed or who are not meeting glycemic goals. E

- Use of point-of-care testing for A1C provides the opportunity for more timely treatment changes. $\mathrm{E}$

For patients in whom A1C and measured blood glucose appear discrepant, clinicians should consider 
the possibilities of hemoglobinopathy or altered red blood cell turnover and the options of more frequent and/or different timing of SMBG or CGM use. Other measures of chronic glycemia such as fructosamine are available, but their linkage to average glucose and their prognostic significance are not as clear as for A1C.

\section{A1C Goals}

See pages 18-20 for glycemic goals for children and pregnant women. The complete 2016 Standards includes additional goals for children and pregnant women.

\section{Recommendations}

- A reasonable A1C goal for many nonpregnant adults is $<7 \%$ (53 $\mathrm{mmol} / \mathrm{mol}$ ). A

- Providers might reasonably suggest more stringent $\mathrm{A} 1 \mathrm{C}$ goals (such as $<6.5 \%$ [ $48 \mathrm{mmol} / \mathrm{mol}]$ ) for selected individual patients if this can be achieved without significant hypoglycemia or other adverse effects of treatment. Appropriate patients might include those with a short duration of diabetes, type 2 diabetes treated with lifestyle or metformin only, long life expectancy, or no significant CVD. C

- Less stringent A1C goals (such as $<8 \%$ [64 $\mathrm{mmol} / \mathrm{mol}]$ ) may be appropriate for patients with a history of severe hypoglycemia, limited life expectancy, advanced microvascular or macrovascular complications, extensive comorbid conditions, or long-standing diabetes in whom the general goal is difficult to attain despite DSME,

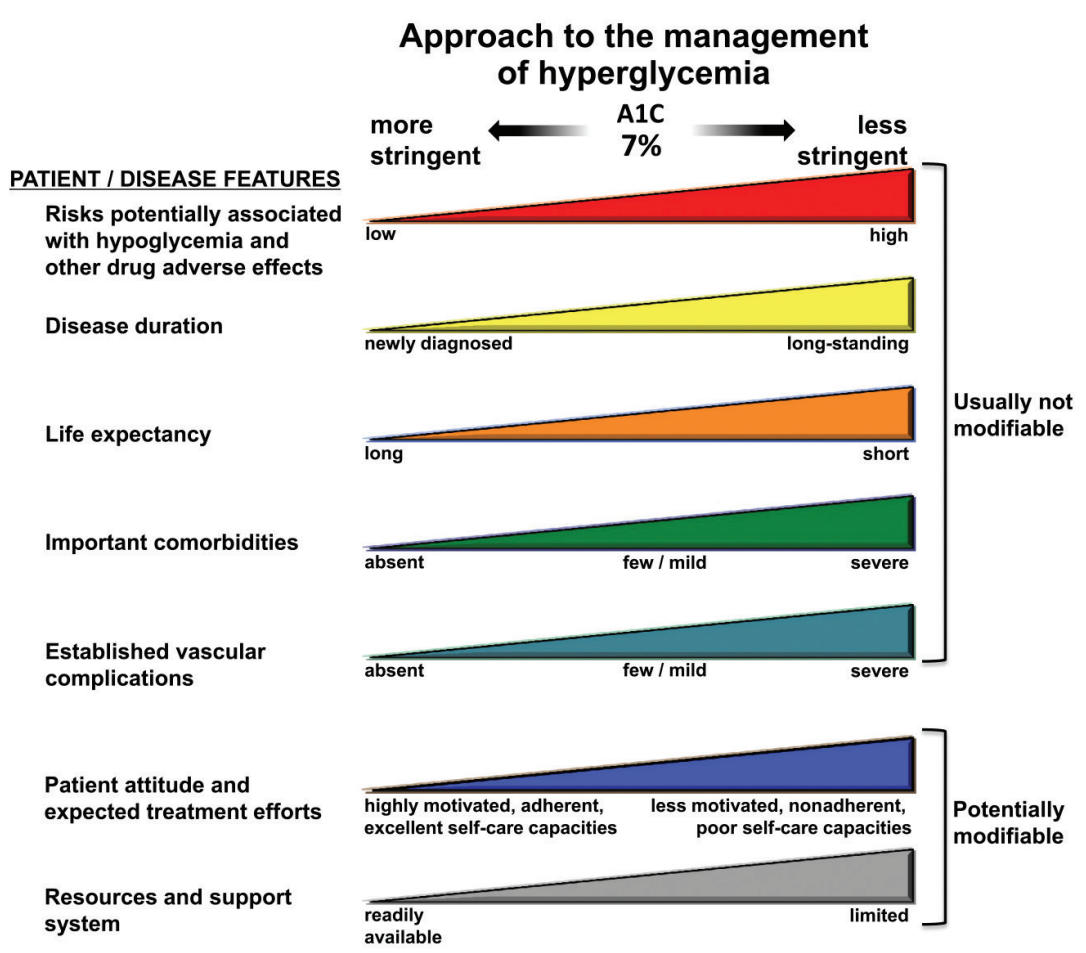

FIGURE 1. Depicted are patient and disease factors used to determine optimal $\mathrm{A} 1 \mathrm{C}$ targets. Characteristics and predicaments toward the left justify more stringent efforts to lower A1C; those toward the right suggest less stringent efforts. Adapted with permission from Inzucchi SE, Bergenstal RM, Buse JB, et al. Management of hyperglycemia in type 2 diabetes, 2015: a patient-centered approach: update to a position statement of the American Diabetes Association and the European Association for the Study of Diabetes. Diabetes Care 2015;38:140-149.

appropriate glucose monitoring, and effective doses of multiple glucose-lowering agents, including insulin. B

Glycemic control achieved using A1C targets of $<7 \%(53 \mathrm{mmol} / \mathrm{mol})$ has been shown to reduce microvascular complications of diabetes, and, in type 1 , mortality. If implemented soon after the diagnosis of diabetes, this target is associated with long-term reduction in macrovascular disease.

See Figure 1 for patient-specific and disease factors used to determine optimal A1C targets. Recommended glycemic targets are provided in Table 6. The recommendations are based on those for A1C values, with blood glucose levels that appear to correlate with achievement of an A1C of $<7 \%(53 \mathrm{mmol} / \mathrm{mol})$.

\section{Hypoglycemia}

\section{Recommendations}

- Individuals at risk for hypoglycemia should be asked about symptomatic and asymptomatic hypoglycemia at each encounter. C

- Glucose (15-20 g) is the preferred treatment for the conscious individual with hypoglycemia, although any form of carbohydrate that contains glucose may be used. Fifteen minutes after treatment, if SMBG shows continued hypoglycemia, the treatment should be repeated. Once SMBG returns to normal, the individual should consume a meal or snack to prevent recurrence of hypoglycemia. E

- Glucagon should be prescribed for all individuals at increased risk of severe hypoglycemia, defined as hypoglycemia requiring assistance, and caregivers or family members of these individuals should be instructed on its administration. Glucagon administration is not limited to health care professionals. E 
- Hypoglycemia unawareness or one or more episodes of severe hypoglycemia should trigger reevaluation of the treatment regimen. $E$

- Insulin-treated patients with hypoglycemia unawareness or an episode of severe hypoglycemia should be advised to raise their glycemic targets to strictly avoid further hypoglycemia for at least several weeks in order to partially reverse hypoglycemia unawareness and reduce their risk of future episodes. A

- Ongoing assessment of cognitive function is suggested with increased vigilance for hypoglycemia by the clinician, patient, and caregivers if low cognition and/or declining cognition is found. $\mathrm{B}$

\section{OBESITY MANAGEMENT FOR THE TREATMENT OF TYPE 2 DIABETES}

There is strong and consistent evidence that obesity management can delay progression from prediabetes to type 2 diabetes and benefits type 2 diabetes treatment. In overweight and obese patients with type 2 diabetes, modest weight loss, defined as sustained reduction of $5 \%$ of initial body weight, has been shown to improve glycemic control and triglycerides and to reduce the need for glucose-lowering medication. Sustained weight loss of $\geq 7 \%$ is optimal.

\section{Assessment}

\section{Recommendation}

- At each patient encounter, BMI should be calculated and documented in the medical record. B

In Asian Americans, the cutoff points to define overweight and obesity are lower: normal $\left(<23 \mathrm{BMI} \mathrm{kg} / \mathrm{m}^{2}\right)$, overweight (BMI $23.0-27.4 \mathrm{~kg} / \mathrm{m}^{2}$ ), obese (BMI $27.5-37.4 \mathrm{~kg} / \mathrm{m}^{2}$ ), and extremely obese (BMI $\left.\geq 37.5 \mathrm{~kg} / \mathrm{m}^{2}\right)$. Providers should advise overweight and obese patients that higher BMIs increase the risk of CVD and allcause mortality. Providers should assess each patient's readiness to achieve weight loss and jointly determine weight loss goals and intervention strategies. Strategies include diet, physical activity, behavioral therapy, pharmacological therapy, and bariatric surgery. The latter two strategies may be prescribed for carefully selected patients as adjuncts to diet, physical activity, and behavioral therapy.

\section{Diet, Physical Activity, and Behavioral Therapy}

\section{Recommendations}

- Diet, physical activity, and behavioral therapy designed to achieve a $5 \%$ weight loss should be prescribed for overweight and obese patients with type 2 diabetes who are ready to achieve weight loss. A

TABLE 6. Summary of Glycemic Recommendations for Nonpregnant Adults With Diabetes

\begin{tabular}{ll}
\hline A1C & $<7.0 \%(53 \mathrm{mmol} / \mathrm{mol})^{\star}$ \\
\hline Preprandial capillary plasma glucose & $80-130 \mathrm{mg} / \mathrm{dL}^{\star}(4.4-7.2 \mathrm{mmol} / \mathrm{L})$ \\
\hline $\begin{array}{l}\text { Peak postprandial capillary plasma } \\
\text { glucose }\end{array}$ & $<180 \mathrm{mg} / \mathrm{dL}^{*}(10.0 \mathrm{mmol} / \mathrm{L})$ \\
\hline
\end{tabular}

*More or less stringent glycemic goals may be appropriate for individual patients. Goals should be individualized based on duration of diabetes, age/life expectancy, comorbid conditions, known CVD or advanced microvascular complications, hypoglycemia unawareness, and individual patient considerations.

†Postprandial glucose may be targeted if A1C goals are not met despite reaching preprandial glucose goals. Postprandial glucose measurements should be made 1-2 hours after the beginning of the meal, generally peak levels in patients with diabetes.

- Such interventions should be high-intensity ( $\geq 16$ sessions in 6 months) and focus on diet, physical activity, and behavioral strategies to achieve a 500-750 $\mathrm{kcal} /$ day energy deficit. A

- Diets that provide the same caloric restriction but differ in protein, carbohydrate, and fat content are equally effective in achieving weight loss. A

- For patients who achieve shortterm weight loss goals, long-term ( $\geq 1$ year), comprehensive weight maintenance programs should be prescribed. Such programs should provide at least monthly contact and encourage ongoing monitoring of body weight (at least weekly), continued consumption of a reduced-calorie diet, and participation in high levels of physical activity (200-300 min/week). A

- To achieve weight loss of $>5 \%$, short-term (3-month) highintensity lifestyle interventions that use very-low-calorie diets $(\leq 800 \mathrm{kcal} / \mathrm{day})$ and total meal replacements may be prescribed for carefully selected patients by trained practitioners in medical care settings with close medical monitoring. To maintain weight loss, such programs must incorporate long-term, comprehensive weight maintenance counseling. B

\section{Pharmacotherapy}

\section{Recommendations}

- When choosing glucose-lowering medications for overweight or obese patients with type 2 diabetes, consider their effect on weight. $\mathrm{E}$

- Whenever possible, minimize medications for comorbid conditions that are associated with weight gain. $\mathrm{E}$

- Weight loss medications may be effective as adjuncts to diet, physical activity, and behavioral counseling for selected patients with type 2 diabetes and a BMI $\geq 27 \mathrm{~kg} / \mathrm{m}^{2}$. Potential benefits must 
be weighed against the potential risks of the medications. A

- If a patient's response to weight loss medications is $<5 \%$ after 3 months, or if there are any safety or tolerability issues at any time, the medication should be discontinued, and alternative medications or treatment approaches should be considered. A

\section{Bariatric Surgery}

\section{Recommendations}

- Bariatric surgery may be considered for adults with a BMI $>35 \mathrm{~kg} / \mathrm{m}^{2}$ and type 2 diabetes, especially if diabetes or associated comorbidities are difficult to control with lifestyle and pharmacological therapy. B

- Patients with type 2 diabetes who have undergone bariatric surgery need lifelong lifestyle support and annual medical monitoring, at a minimum. B

- Although small trials have shown a glycemic benefit of bariatric surgery in patients with type 2 diabetes and a BMI of $30-35 \mathrm{~kg} / \mathrm{m}^{2}$, there is currently insufficient evidence to generally recommend surgery for patients with a BMI $\leq 35 \mathrm{~kg} / \mathrm{m}^{2}$. E

Younger age, shorter duration of type 2 diabetes, lower A1C, higher serum insulin levels, and nonuse of insulin have all been associated with higher diabetes remission rates after bariatric surgery.

\section{APPROACHES TO GLYCEMIC TREATMENT}

\section{Pharmacological Therapy for Type 1 Diabetes}

\section{Recommendations}

- Most people with type 1 diabetes should be treated with multiple-dose insulin injections (three to four injections per day of basal and prandial insulin) or continuous subcutaneous insulin infusion therapy. A

- Consider educating individuals with type 1 diabetes on matching prandial insulin doses to carbohydrate intake, premeal blood glucose levels, and anticipated physical activity. E

- Most individuals with type 1 diabetes should use insulin analogs to reduce hypoglycemia risk. A

For patients with frequent nocturnal hypoglycemia and/or hypoglycemia unawareness, a sensor-augmented pump with a low glucose threshold feature may be considered.

\section{Pharmacological Therapy for Type 2 Diabetes}

\section{Recommendations}

- Metformin, if not contraindicated and if tolerated, is the preferred initial pharmacological agent for type 2 diabetes. A

- Consider initiating insulin therapy (with or without additional agents) in patients with newly diagnosed type 2 diabetes who are symptomatic and/or have markedly elevated blood glucose levels or A1C. E

- If noninsulin monotherapy at the maximum tolerated dose does not achieve or maintain the A1C target over 3 months, then add a second oral agent, a glucagon-like peptide 1 receptor agonist, or basal insulin. A

- A patient-centered approach should be used to guide the choice of pharmacological agents. Considerations include efficacy, cost, potential side effects, weight, comorbidities, hypoglycemia risk, and patient preferences. $\mathrm{E}$

- For patients with type 2 diabetes who are not achieving glycemic goals, insulin therapy should not be delayed. $\mathrm{B}$

Figure 2 emphasizes drugs commonly used in the United States and/or Europe.

A comprehensive list of the properties of available glucose-lowering agents in the United States and
Europe that may guide individualized treatment choices in patients with type 2 diabetes is available in the complete 2016 Standards.

Many patients with type 2 diabetes eventually require and benefit from insulin therapy. The progressive nature of type 2 diabetes and its therapies should be regularly and objectively explained to patients. Providers should avoid using insulin as a threat or describing it as a failure or punishment. Equipping patients with an algorithm for self-titration of insulin doses based on SMBG results improves glycemic control in patients with type 2 diabetes who are initiating insulin.

\section{CARDIOVASCULAR DISEASE AND RISK MANAGEMENT}

Atherosclerotic CVD (ASCVD)—de-

fined as acute coronary syndromes, a history of myocardial infarction, stable or unstable angina, coronary or other arterial revascularization, stroke, transient ischemic attack, or peripheral arterial disease (PAD) presumed to be of atherosclerotic origin-is the leading cause of morbidity and mortality for individuals with diabetes and is the largest contributor to the direct and indirect costs of diabetes. In all patients with diabetes, cardiovascular risk factors should be systematically assessed at least annually. These risk factors include dyslipidemia, hypertension, smoking, a family history of premature coronary disease, and the presence of albuminuria.

Numerous studies have shown the efficacy of controlling individual cardiovascular risk factors in preventing or slowing ASCVD in people with diabetes. Large benefits are seen when multiple risk factors are addressed simultaneously. There is evidence that measures of 10-year coronary heart disease risk among U.S. adults with diabetes have improved significantly over the past decade, and ASCVD morbidity and mortality have decreased. 


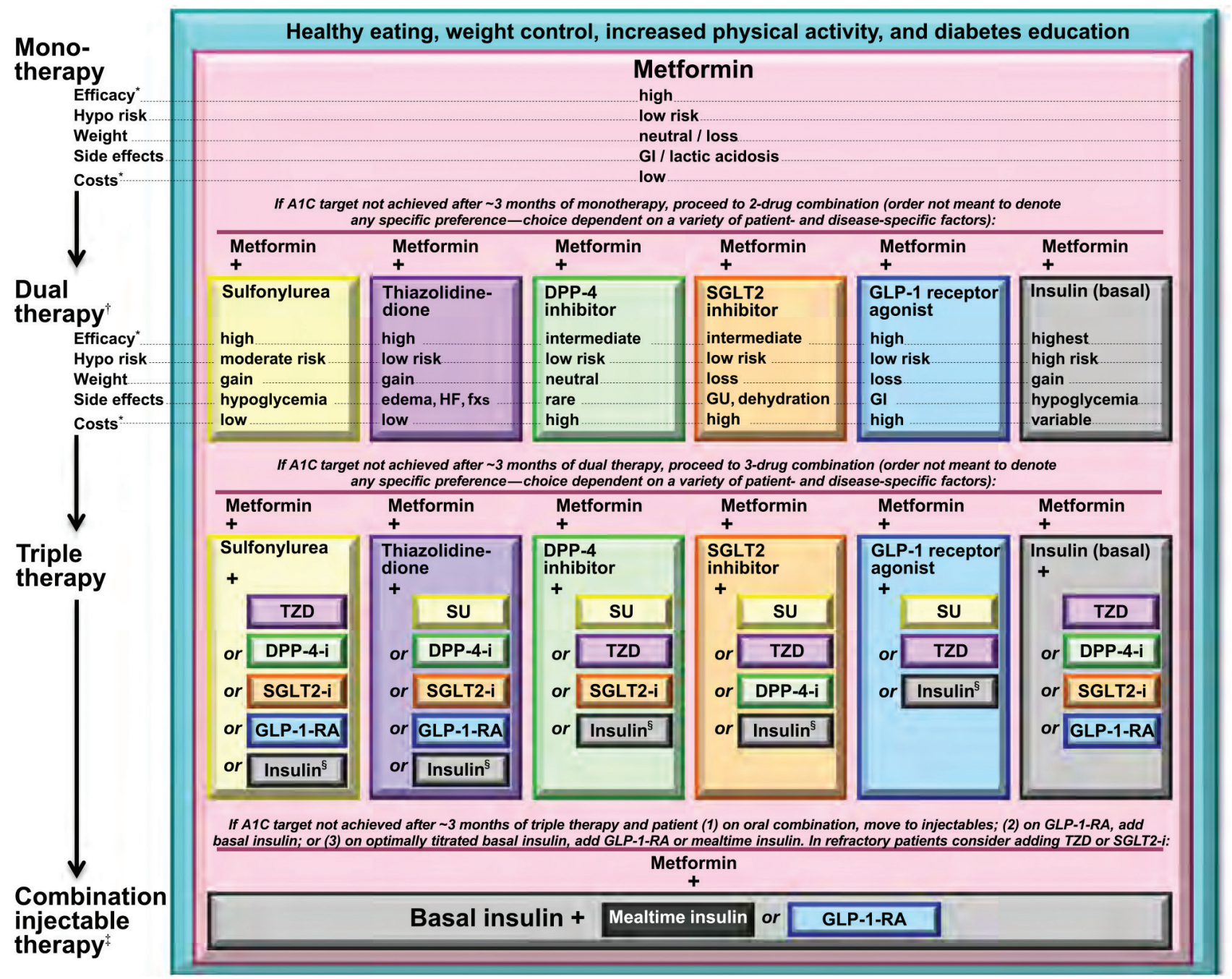

FIGURE 2. Antihyperglycemic therapy in type 2 diabetes: general recommendations. The order in the chart was determined by historical availability and the route of administration, with injectables to the right; it is not meant to denote any specific preference. Potential sequences of antihyperglycemic therapy for patients with type 2 diabetes are displayed, with the usual transition moving vertically from top to bottom (although horizontal movement within therapy stages is also possible, depending on the circumstances). DPP-4-i, DPP-4 inhibitor; fxs, fractures; GI, gastrointestinal; GLP-1-RA, GLP-1 receptor agonist; GU, genitourinary; HF, heart failure; Hypo, hypoglycemia; SGLT2-i, SGLT2 inhibitor; SU, sulfonylurea; TZD, thiazolidinedione. *See ref. 17 in the full SOC document for description of efficacy categorization. $\dagger$ Consider starting at this stage when $\mathrm{A} 1 \mathrm{C}$ is $\geq 9 \%(75 \mathrm{mmol} / \mathrm{mol})$. $\ddagger$ Consider starting at this stage when blood glucose is $\geq 300-350 \mathrm{mg} / \mathrm{dL}(16.7-19.4 \mathrm{mmol} / \mathrm{L})$ and $/$ or $\mathrm{A} 1 \mathrm{C}$ is $\geq 10-12 \%(86-108 \mathrm{mmol} / \mathrm{mol})$, especially if symptomatic or catabolic features are present, in which case basal insulin + mealtime insulin is the preferred initial regimen. \$Usually a basal insulin (NPH, glargine, detemir, degludec). Adapted with permission from Inzucchi SE, Bergenstal RM, Buse JB, et al. Management of hyperglycemia in type 2 diabetes, 2015: a patient-centered approach: update to a position statement of the American Diabetes Association and the European Association for the Study of Diabetes. Diabetes Care 2015;38:140-149.

\section{Blood Pressure Control}

\section{Recommendations}

- People with diabetes and hypertension should be treated to a systolic blood pressure (SBP) of $<140 \mathrm{mmHg}$ or a blood pressure goal of $<140 / 90 \mathrm{mmHg}$. A
- Lower blood pressure targets may be appropriate for certain individuals with diabetes such as younger patients, those with albuminuria, and/or those with hypertension and one or more additional ASCVD risk factors if they can be achieved without undue treatment burden. $\mathrm{C}$
- Patients with blood pressure $>120 / 80$ mmHg should be advised on lifestyle changes to reduce blood pressure. B

- Patients with confirmed officebased blood pressure $>140 / 90$ $\mathrm{mmHg}$ should, in addition to lifestyle therapy, have prompt 
initiation and timely subsequent titration of pharmacological therapy to achieve blood pressure goals. A

- In older adults, pharmacological therapy to achieve treatment goals of $<130 / 70 \mathrm{mmHg}$ are not recommended; treating to an SBP $<130 \mathrm{mmHg}$ has not been shown to improve cardiovascular outcomes, and treating to a diastolic blood pressure (DBP) $<70 \mathrm{mmHg}$ has been associated with higher mortality. C

- Pharmacological therapy for patients with diabetes and hypertension should comprise a regimen that includes either an ACE inhibitor or an angiotensin receptor blocker (ARB) but not both. B If one class is not tolerated, the other should be substituted. C

- Multiple-drug therapy (including a thiazide diuretic and $\mathrm{ACE}$ inhibitor/ARB, at maximal doses) is generally required to achieve blood pressure targets. B

- If ACE inhibitors, ARBs, or diuretics are used, serum creatinine/ estimated glomerular filtration rate (eGFR) and serum potassium levels should be monitored. E

\section{Lipid Management}

\section{Recommendations}

- Obtain a lipid profile at initiation of statin therapy and periodically thereafter because doing so may help monitor the response to therapy and inform about adherence. E

- Lifestyle modification focusing on weight loss (if indicated); the reduction of saturated fat, trans fat, and cholesterol intake; increased intake of omega-3 fatty acids, viscous fiber, and plant stanols/sterols; and increased physical activity should be recommended to improve the lipid profile in patients with diabetes. A

- Intensify lifestyle therapy and optimize glycemic control for patients with elevated triglyceride levels $(\geq 150 \mathrm{mg} / \mathrm{dL}[1.7 \mathrm{mmol} / \mathrm{L}])$ and $/$ or low HDL cholesterol $(<40 \mathrm{mg} / \mathrm{dL}$
[1.0 mmol/L] for men, $<50 \mathrm{mg} / \mathrm{dL}$ [1.3 mmol/L] for women). C

- For patients with fasting triglyceride levels $\geq 500 \mathrm{mg} / \mathrm{dL}$ (5.7 $\mathrm{mmol} / \mathrm{L}$ ), evaluate for secondary causes of hypertriglyceridemia and consider medical therapy to reduce the risk of pancreatitis. C

- Combination therapy (statin/ fibrate) has not been shown to improve ASCVD outcomes and is generally not recommended. A However, therapy with statin and fenofibrate may be considered for men with both a triglyceride level $\geq 204 \mathrm{mg} / \mathrm{dL}(2.3 \mathrm{mmol} / \mathrm{L})$ and an HDL cholesterol level $\leq 34 \mathrm{mg} / \mathrm{dL}$ (0.9 mmol/L). B

- Combination therapy (statin/niacin) has not been shown to provide additional cardiovascular benefit beyond statin therapy alone and may increase the risk of stroke and is not generally recommended. A

Table 7 provides recommendations for statin and combination therapy in people with diabetes. Table 8 outlines high- and moderate-intensity statin therapy.

\section{Antiplatelet Agents}

\section{Recommendations}

- Consider aspirin therapy (75-162 $\mathrm{mg} /$ day) as a primary prevention strategy in those with type 1 or type 2 diabetes who are at increased cardiovascular risk (10year risk $>10 \%)$. This includes most men and women with diabetes who are $\geq 50$ years of age who have at least one additional major risk factor (i.e., family history of premature ASCVD, hypertension, smoking, dyslipidemia, or albuminuria) and are not at increased risk of bleeding. C

- Aspirin should not be recommended for ASCVD prevention for adults with diabetes at low ASCVD risk (10-year ASCVD risk $<5 \%$ ) such as men and women with diabetes who are $<50$ years of age with no major additional ASCVD risk factors because the potential adverse effects from bleeding likely offset the potential benefits. C

- In patients with diabetes who are $<50$ years of age with multiple other risk factors (10-year risk 5-10\%), clinical judgment is required. $\mathrm{E}$

- Use aspirin therapy (75-162 mg/day) as a secondary prevention strategy in those with diabetes and a history of ASCVD. A

- For patients with ASCVD and documented aspirin allergy, clopidogrel $(75 \mathrm{mg} /$ day) should be used. B

- Dual antiplatelet therapy is reasonable for up to 1 year after an acute coronary syndrome. B

\section{MICROVASCULAR COMPLICATIONS AND FOOT CARE}

Intensive diabetes management with the goal of achieving near-normoglycemia has been shown in large, prospective, randomized studies to delay the onset and progression of microvascular complications.

\section{Diabetic Kidney Disease}

\section{Recommendations}

- Assess urinary albumin (e.g., spot urinary albumin-to-creatinine ratio [UACR]) and eGFR at least annually in patients with type 1 diabetes with duration of $\geq 5$ years, in all patients with type 2 diabetes, and in all patients with comorbid hypertension. B

- Optimize glucose control to reduce the risk or slow the progression of diabetic kidney disease (DKD). A

Complications of kidney disease correlate with level of kidney function.

Screening can be performed by assessing UACR in a random spot urine collection; timed or 24-h collections are more burdensome and add little to prediction or accuracy. Two of three specimens collected within a 3- to 6-month period should be 
TABLE 7. Recommendations for Statin and Combination Treatment in People With Diabetes

\begin{tabular}{|c|c|c|}
\hline Age & Risk factors & $\begin{array}{l}\text { Recommended } \\
\text { statin intensity* }\end{array}$ \\
\hline$<40$ years & $\begin{array}{c}\text { None } \\
\text { ASCVD risk factor }(\mathrm{s})^{\star *} \\
\text { ASCVD }\end{array}$ & $\begin{array}{l}\text { None } \\
\text { Moderate or high } \\
\text { High }\end{array}$ \\
\hline 40-75 years & $\begin{array}{c}\text { None } \\
\text { ASCVD risk factors } \\
\text { ASCVD } \\
\text { ACS and LDL cholesterol }>50 \mathrm{mg} / \mathrm{dL} \\
(1.3 \mathrm{mmol} / \mathrm{L}) \text { in patients who cannot } \\
\text { tolerate high-dose statins }\end{array}$ & $\begin{array}{c}\text { Moderate } \\
\text { High } \\
\text { High } \\
\text { Moderate plus } \\
\text { ezetimibe }\end{array}$ \\
\hline$>75$ years & $\begin{array}{c}\text { None } \\
\text { ASCVD risk factors } \\
\text { ASCVD } \\
\text { ACS and LDL cholesterol }>50 \mathrm{mg} / \mathrm{dL} \\
(1.3 \mathrm{mmol} / \mathrm{L}) \text { in patients who cannot } \\
\text { tolerate high-dose statins }\end{array}$ & $\begin{array}{c}\text { Moderate } \\
\text { Moderate or high } \\
\text { High } \\
\text { Moderate plus } \\
\text { ezetimibe }\end{array}$ \\
\hline
\end{tabular}

*In addition to lifestyle therapy.

**ASCVD risk factors include $L D L$ cholesterol $\geq 100 \mathrm{mg} / \mathrm{dL}(2.6 \mathrm{mmol} / \mathrm{L})$, high blood pressure, smoking, overweight and obesity, and family history of premature ASCVD. ACS, acute coronary syndrome.

TABLE 8. High- and Moderate-Intensity Statin Therapy*

\begin{tabular}{cc}
\hline High-intensity statin therapy & Moderate-intensity statin therapy \\
\hline Lowers LDL cholesterol by $\geq 50 \%$ & Lowers $L D L$ cholesterol by $30 \%$ to $<50 \%$ \\
Atorvastatin $40-80 \mathrm{mg}$ & Atorvastatin $10-20 \mathrm{mg}$ \\
Rosuvastatin $20-40 \mathrm{mg}$ & Rosuvastatin $5-10 \mathrm{mg}$ \\
& Simvastatin $20-40 \mathrm{mg}$ \\
& Pravastatin $40-80 \mathrm{mg}$ \\
Lovastatin $40 \mathrm{mg}$ \\
Fluvastatin $X \mathrm{~L} 80 \mathrm{mg}$ \\
Pitavastatin $2-4 \mathrm{mg}$
\end{tabular}

*Once-daily dosing.

abnormal before considering a patient to have albuminuria.

Blood pressure levels $<140 / 90$ $\mathrm{mmHg}$ in diabetes are recommended to reduce the risk or slow the progression of DKD. ACE inhibitors have been shown to reduce major CVD events in patients with diabetes, supporting their use in those with albuminuria (a CVD risk factor).

Combined use of ACE inhibitors plus $A R B s$ showed no benefit on CVD or DKD and higher adverse event rates. Thus, combination therapy should be avoided

Recommendations for the management of chronic kidney disease (CKD) in people with diabetes are summarized in Table 9.

\section{Diabetic Retinopathy}

\section{Recommendations}

- Optimize glycemic control to reduce the risk or slow the progression of diabetic retinopathy. A

- Optimize blood pressure and serum lipid control to reduce the risk or slow the progression of diabetic retinopathy. A

- Adults with type 1 diabetes should have an initial dilated and comprehensive eye examination by an ophthalmologist or optometrist within 5 years after the onset of diabetes. B

- Patients with type 2 diabetes should have an initial dilated and comprehensive eye examination by an ophthalmologist or optometrist at the time of the diabetes diagnosis. $\mathrm{B}$

- If there is no evidence of retinopathy for one or more annual eye exams, then exams every 2 years may be considered. If any level of diabetic retinopathy is present, subsequent dilated retinal examinations for patients with type 1 or type 2 diabetes should be repeated at least annually by an ophthalmologist or optometrist. If retinopathy is progressing or sight-threatening, then examinations will be required more frequently. B

\section{Neuropathy}

\section{Recommendations}

- All patients should be assessed for diabetic peripheral neuropathy (DPN) starting at diagnosis of type 2 diabetes and 5 years after the diagnosis of type 1 diabetes and at least annually thereafter. B

- Symptoms and signs of autonomic neuropathy should be assessed in patients with microvascular and neuropathic complications. E

- Optimize glucose control to prevent or delay the development of neuropathy in patients with type 1 diabetes $\mathrm{A}$ and to slow the progression of neuropathy in patients with type 2 diabetes. B

Clinical tests to detect DPN include pinprick sensation, vibration perception with a $128-\mathrm{Hz}$ tuning fork, and 10-g monofilament.

DPN can be debilitating and may be treated with pregabalin, duloxetine, and tapentadol. For severe, persistent 
TABLE 9. Management of CKD in Diabetes

\begin{tabular}{|c|c|}
\hline $\begin{array}{c}\text { GFR } \\
\left(\mathrm{mL} / \mathrm{min} / 1.73 \mathrm{~m}^{2}\right)\end{array}$ & Recommended management \\
\hline All patients & Yearly measurement of creatinine, UACR, potassium \\
\hline \multirow{7}{*}{$45-60$} & $\begin{array}{l}\text { Referral to a nephrologist if possibility for nondiabetic kidney disease exists (duration of type } \\
1 \text { diabetes }<10 \text { years, persistent albuminuria, abnormal findings on renal ultrasound, resistant } \\
\text { hypertension, rapid fall in eGFR, or active urinary sediment on urine microscopic examination) }\end{array}$ \\
\hline & Consider the need for dose adjustment of medications \\
\hline & Monitor eGFR every 6 months \\
\hline & $\begin{array}{l}\text { Monitor electrolytes, bicarbonate, hemoglobin, calcium, phosphorus, and parathyroid hor- } \\
\text { mone at least yearly }\end{array}$ \\
\hline & Assure vitamin D sufficiency \\
\hline & Consider bone density testing \\
\hline & Referral for dietary counseling \\
\hline \multirow{3}{*}{$30-44$} & Monitor eGFR every 3 months \\
\hline & $\begin{array}{l}\text { Monitor electrolytes, bicarbonate, calcium, phosphorus, parathyroid hormone, hemoglobin, } \\
\text { albumin, and weight every } 3-6 \text { months }\end{array}$ \\
\hline & Consider the need for dose adjustment of medications \\
\hline$<30$ & Referral to a nephrologist \\
\hline
\end{tabular}

pain, amitriptyline, venlafaxine, gabapentin, and opioids may be used. A tailored and stepwise approach is recommended to achieve pain reduction.

The symptoms and signs of autonomic dysfunction include hypoglycemia unawareness, resting tachycardia, orthostatic hypotension, gastroparesis, constipation, diarrhea, fecal incontinence, neurogenic bladder, and sudomotor dysfunction. In men, diabetic autonomic neuropathy may cause erectile dysfunction and/or retrograde ejaculation.

Gastrointestinal neuropathies may involve any portion of the gastrointestinal tract. Gastroparesis should be suspected in individuals with erratic glucose control or with upper gastrointestinal symptoms. Constipation is the most common lower-gastrointestinal symptom but can alternate with episodes of diarrhea.

Recurrent urinary tract infections, pyelonephritis, incontinence, or a palpable bladder should evoke evaluation for bladder dysfunction.

\section{Foot Care}

\section{Recommendations}

- Perform a comprehensive foot evaluation each year to identify risk factors for ulcers and amputations. B

- The examination should include inspection of the skin; assessment of foot deformities; neurological assessment, including 10-g monofilament testing and pinprick or vibration testing or assessment of ankle reflexes; and vascular assessment, including pulses in the legs and feet. B

Patients with prior amputation, foot deformities, PAD, poor glycemic control, visual impairment, peripheral neuropathy, or cigarette smoking are high risk.

A complete foot examination should include inspection of skin integrity, identification of musculoskeletal deformities, and assessment of pedal pulses.

Examination should seek to identify loss of protective sensation (LOPS). Absent monofilament sensation suggests LOPS, whereas at least two normal tests (and no abnormal test) rules out LOPS.

Screening for PAD should include a history of claudication and an assessment of pedal pulses. Anklebrachial index evaluation should be performed in patients at 50 years of age and older and should be considered in patients $<50$ years of age who have other PAD risk factors (e.g., smoking, hypertension, dyslipidemia, or duration of diabetes $>10$ years).

Patients with high-risk foot conditions (e.g., history of ulcer or amputation, deformity, loss of protective sensation, or PAD) should be educated about their risk factors and appropriate management. The selection of appropriate footwear and footwear behaviors at home should also be discussed. This may include well-fitted walking shoes or athletic shoes that cushion the feet and redistribute pressure. People with bony deformities or more advanced disease may require custom-fitted shoes.

\section{OLDER ADULTS}

\section{Recommendations}

- Older adults ( $\geq 65$ years of age) who are functional and cognitively intact and have significant life expectancy may receive diabetes care with goals similar to those developed for younger adults. E

- Consider the assessment of medical, functional, mental, and social geriatric domains for diabetes man- 
agement in older adults to provide a framework to determine targets and therapeutic approaches. E

- Glycemic goals for some older adults might reasonably be relaxed using individual criteria, but hyperglycemia leading to symptoms or risk of acute hyperglycemic complications should be avoided in all patients. E

- Hypoglycemia should be avoided in older adults with diabetes. It should be screened for and managed by adjusting glycemic targets and pharmacological interventions. B

- Patients with diabetes residing in long-term care facilities need careful assessment to establish a glycemic goal and to make appropriate choices of glucose-lowering agents based on their clinical and functional status. $\mathrm{E}$

- Other cardiovascular risk factors should be treated in older adults with consideration of the time frame of benefit and the individual patient. Treatment of hypertension is indicated in virtually all older adults, and lipid-lowering and aspirin therapy may benefit those with a life expectancy at least equal to the time frame of primary or secondary prevention trials. E

- When palliative care is needed in older adults with diabetes, strict blood pressure control may not be necessary, and withdrawal of therapy may be appropriate. Similarly,

\section{TABLE 10. Framework for Considering Treatment Goals for Glycemia, Blood Pressure, and Dyslipidemia in Older Adults With Diabetes}

\begin{tabular}{|c|c|c|c|c|c|c|c|c|}
\hline \multirow{2}{*}{$\begin{array}{l}\text { Patient characteris- } \\
\text { tics/health status }\end{array}$} & \multirow[t]{2}{*}{ Rationale } & \multirow{2}{*}{$\begin{array}{l}\text { Reasonable } \\
\text { A1C goalf }\end{array}$} & \multicolumn{2}{|c|}{$\begin{array}{l}\text { Fasting or pre- } \\
\text { prandial glucose }\end{array}$} & \multicolumn{2}{|c|}{ Bedtime glucose } & \multirow{2}{*}{$\begin{array}{l}\text { Blood } \\
\text { pressure } \\
(\mathrm{mmHg})\end{array}$} & \multirow[t]{2}{*}{ Lipids } \\
\hline & & & $\mathrm{mg} / \mathrm{dL}$ & $\mathrm{mmol} / \mathrm{L}$ & $\mathrm{mg} / \mathrm{dL}$ & $\mathrm{mmol} / \mathrm{L}$ & & \\
\hline $\begin{array}{l}\text { Healthy (few coexist- } \\
\text { ing chronic illnesses, } \\
\text { intact cognitive and } \\
\text { functional status) }\end{array}$ & $\begin{array}{l}\text { Longer } \\
\text { remaining life } \\
\text { expectancy }\end{array}$ & $\begin{array}{c}<7.5 \% \\
(58 \mathrm{mmol} / \\
\mathrm{mol})\end{array}$ & 90-130 & $5.0-7.2$ & $90-150$ & $5.0-8.3$ & $<140 / 90$ & $\begin{array}{l}\text { Statin unless } \\
\text { contraindi- } \\
\text { cated or not } \\
\text { tolerated }\end{array}$ \\
\hline $\begin{array}{l}\text { Complex/intermedi- } \\
\text { ate (multiple coexist- } \\
\text { ing chronic illnesses* } \\
\text { or } 2+\text { instrumental } \\
\text { ADL impairments } \\
\text { or mild-to-mod- } \\
\text { erate cognitive } \\
\text { impairment) }\end{array}$ & $\begin{array}{l}\text { Intermediate } \\
\text { remaining life } \\
\text { expectancy, } \\
\text { high treat- } \\
\text { ment burden, } \\
\text { hypoglycemia } \\
\text { vulnerability, } \\
\text { fall risk }\end{array}$ & $\begin{array}{c}<8.0 \% \\
(64 \mathrm{mmol} / \\
\mathrm{mol})\end{array}$ & 90-150 & $5.0-8.3$ & 100-180 & $5.6-10.0$ & $<140 / 90$ & $\begin{array}{l}\text { Statin unless } \\
\text { contraindi- } \\
\text { cated or not } \\
\text { tolerated }\end{array}$ \\
\hline $\begin{array}{l}\text { Very complex/ } \\
\text { poor health (LTC or } \\
\text { end-stage chron- } \\
\text { ic illnesses }{ }^{\star *} \text { or } \\
\text { moderate-to-severe } \\
\text { cognitive impair- } \\
\text { ment or } 2+A D L \\
\text { dependencies) }\end{array}$ & $\begin{array}{l}\text { Limited } \\
\text { remaining life } \\
\text { expectancy } \\
\text { makes benefit } \\
\text { uncertain }\end{array}$ & $\begin{array}{c}<8.5 \% \dagger \\
(69 \mathrm{mmol} / \\
\mathrm{mol})\end{array}$ & 100-180 & $5.6-10.0$ & 110-200 & $6.1-11.1$ & $<150 / 90$ & $\begin{array}{l}\text { Consider } \\
\text { likelihood } \\
\text { of benefit } \\
\text { with statin } \\
\text { (secondary } \\
\text { prevention } \\
\text { more so than } \\
\text { primary) }\end{array}$ \\
\hline
\end{tabular}

This represents a consensus framework for considering treatment goals for glycemia, blood pressure, and dyslipidemia in older adults with diabetes. The patient characteristic categories are general concepts. Not every patient will clearly fall into a particular category. Consideration of patient and caregiver preferences is an important aspect of treatment individualization. Additionally, a patient's health status and preferences may change over time. ADL, activities of daily living.

$\ddagger$ A lower A1C goal may be set for an individual if achievable without recurrent or severe hypoglycemia or undue treatment burden.

*Coexisting chronic illnesses are conditions serious enough to require medications or lifestyle management and may include arthritis, cancer, congestive heart failure, depression, emphysema, falls, hypertension, incontinence, stage 3 or worse chronic kidney disease, myocardial infarction, and stroke. By "multiple," we mean at least three, but many patients may have five or more.

**The presence of a single end-stage chronic illness, such as stage 3-4 congestive heart failure or oxygen-dependent lung disease, chronic kidney disease requiring dialysis, or uncontrolled metastatic cancer, may cause significant symptoms or impairment of functional status and significantly reduce life expectancy.

†A1C of $8.5 \%$ (69 mmol/mol) equates to an estimated average glucose of $\sim 200 \mathrm{mg} / \mathrm{dL}$ (11.1 mmol/L). Looser A1C targets above $8.5 \%(69 \mathrm{mmol} / \mathrm{mol})$ are not recommended as they may expose patients to more frequent higher glucose values and the acute risks from glycosuria, dehydration, hyperglycemic hyperosmolar syndrome, and poor wound healing. 
the intensity of lipid management can be relaxed, and withdrawal of lipid-lowering therapy may be appropriate. E

- Screening for diabetes complications should be individualized in older adults, but particular attention should be paid to complications that would lead to functional impairment. E

- Screening for geriatric syndromes may be appropriate in older adults experiencing limitations in their basic and instrumental activities of daily living because such limitations may affect diabetes self-management. E

- Older adults with diabetes should be considered a high-priority population for depression screening and treatment. B

- Consider diabetes education for the staff of long-term care facilities to improve the management of older adults with diabetes. $\mathrm{E}$

- Overall comfort, prevention of distressing symptoms, and preservation of quality of life and dignity are primary goals for diabetes management at the end of life. $\mathrm{E}$

Older individuals have a higher risk of premature death, coexisting illnesses, depression, and geriatric syndromes, including neurocognitive impairment. Refer to the ADA consensus report "Diabetes in Older Adults" for details.

\section{Treatment Goals}

The care of older adults with diabetes is complicated by their clinical and functional heterogeneity. Providers caring for older adults with diabetes must take this heterogeneity into consideration when setting and prioritizing treatment goals (Table 10).

There are few long-term studies in older adults demonstrating the benefits of intensive glycemic, blood pressure, and lipid control. Patients who are expected to live long enough to reap the benefits of long-term intensive diabetes management, who have good cognitive and physical function, and who choose to do so via shared decision making may be treated using therapeutic interventions and goals similar to those for younger adults with diabetes. Less intensive management goals may be appropriate for those with life-limiting complications, comorbid conditions, or substantial cognitive or functional impairment. However, glycemic goals at a minimum should avoid acute complications of diabetes, including dehydration, poor wound healing, hyperglycemic hyperosmolar coma, and hypoglycemia. DSME and ongoing DSMS are vital components of diabetes care.

Older adults with diabetes are likely to benefit from control of other cardiovascular risk factors. Evidence is strong for treatment of hypertension. There is less evidence for lipid-lowering and aspirin therapy, although the benefits of these interventions are likely to apply to older adults whose life expectancies equal or exceed the time frames of clinical prevention trials.

\section{Pharmacological Therapy}

Special care is required in prescribing and monitoring pharmacological therapy in older adults. Factors include cost, coexisting conditions (e.g., renal status), and hypoglycemia. The patient's living situation must be considered because it may affect diabetes management and support. See the complete 2016 Standards for medications and prescribing information specific to older adults.

\section{Treatment in Skilled Nursing Facilities and Nursing Homes} Management of diabetes is unique in the long-term care (LTC) setting (i.e., nursing homes and skilled nursing facilities). Individualization of health care is important for all patients. However, practical guidance is needed for both medical providers and LTC staff and caregivers. The American Medical Director's Association guidelines offer a 12-step training program for LTC staff.

Older adults with diabetes in LTC are especially vulnerable to hypoglyce- mia because of their disproportionately higher number of complications and comorbidities. Alert strategies should be in place for hypoglycemia (blood glucose $<70 \mathrm{mg} / \mathrm{dL}[3.9 \mathrm{mmol} / \mathrm{L}]$ ) and hyperglycemia (blood glucose $>250 \mathrm{mg} / \mathrm{dL}$ [13.9 mmol/L]).

For patients in the LTC setting, special attention should be given to nutritional considerations, end of life care, and diabetes management in those with advanced disease. Acknowledging the limited benefit of intensive glycemic control in people with advanced disease can guide A1C goals and determine the use or withdrawal of medications.

\section{CHILDREN AND \\ ADOLESCENTS}

See page 5 for screening and diagnostic testing information. The following recommendations were developed for children and adolescents with type 1 diabetes. However, the guidelines are the same for children and adolescents with type 2 diabetes, with the addition of blood pressure measurement, a fasting lipid panel, assessment for albumin excretion, and dilated eye examination at the time of type $2 \mathrm{di}$ abetes diagnosis.

\section{Glycemic Control}

\section{Recommendations}

- An A1C goal of $<7.5 \%$ (58 mmol/ mol) is recommended across all pediatric age-groups. E

The benefit of A1C control should be balanced against the risk of hypoglycemia and the developmental burden of intensive regimens for children and youth.

\section{Hypertension}

\section{Recommendations}

- Blood pressure should be measured at each routine visit. Children found to have high-normal blood pressure (SBP or DBP $\geq 90$ th percentile for age, sex, and height) or hypertension ( $\geq 95$ th percentile for age, sex, and height) 
should have blood pressure confirmed on three separate days. B

Blood pressure measurements should be determined using the appropriate size cuff and with the child seated and relaxed. ACE inhibitors or ARBs should be considered as first-line treatment, following appropriate reproductive counseling due to teratogenic effects.

\section{Dyslipidemia}

\section{Recommendations}

- Obtain a fasting lipid profile on children $\geq 10$ years of age soon after diabetes diagnosis (after glucose control has been established). E

- If lipids are abnormal, annual monitoring is reasonable. If $\mathrm{LDL}$ cholesterol values are within the accepted risk levels $(<100 \mathrm{mg} / \mathrm{dL}$ [2.6 $\mathrm{mmol} / \mathrm{L}]$ ), a lipid profile repeated every 3-5 years is reasonable. E

Lipids should be obtained at diagnosis of type 2 diabetes because of the increased likelihood of comorbid conditions.

\section{Autoimmune Conditions}

Because of the increased frequency of other autoimmune diseases in type 1 diabetes, screening for thyroid dysfunction and celiac disease should be considered.

\section{MANAGEMENT OF DIABETES IN PREGNANCY}

\section{Pregestational Diabetes}

\section{Recommendations}

- Provide preconception counseling that addresses the importance of glycemic control as close to normal as is safely possible, ideally $<6.5 \%$ ( $48 \mathrm{mmol} / \mathrm{mol})$, to reduce the risk of congenital anomalies. B

- Family planning should be discussed and effective contraception should be prescribed and used until a woman is prepared and ready to become pregnant. $A$

- Women with preexisting type 1 or type 2 diabetes who are planning pregnancy or who have become pregnant should be counseled on the risk of development and/or progression of diabetic retinopathy. Eye examinations should occur before pregnancy or in the first trimester and then be monitored every trimester and for 1 year postpartum as indicated by degree of existing retinopathy. $B$

Due to the complexity of insulin management in pregnancy, referral to a specialized center offering team-based care (including highrisk obstetrician, endocrinologist, dietitian, nurse, and social worker, as needed) is recommended if this resource is available.

\section{Gestational Diabetes Mellitus}

\section{Recommendations}

- Lifestyle change is an essential component of GDM management and may suffice for treatment for many women. Medications should be added if needed to achieve glycemic targets. A

- Preferred medications in GDM are insulin and metformin; glyburide may be used but appears to have a higher rate of neonatal hypoglycemia and macrosomia than insulin or metformin, and other agents have not been adequately studied. Most oral agents cross the placenta, and all lack long-term safety data. A

\section{General Principles for the Management of Diabetes in Pregnancy}

\section{Recommendations}

- Potentially teratogenic medications (e.g., ACE inhibitors and statins) should be avoided in sexually active women of childbearing age who are not using reliable contraception. B

- Fasting, preprandial, and postprandial SMBG is recommended in both GDM and pregestational diabetes in pregnancy to achieve glycemic control. B
- Because of increased red blood cell turnover, A1C is lower in normal pregnancy than in nondiabetic, nonpregnant women. The A1C target in pregnancy is $6-6.5 \%(42-48 \mathrm{mmol} / \mathrm{mol})$; $<6 \%(42 \mathrm{mmol} / \mathrm{mol})$ may be optimal if this can be achieved without significant hypoglycemia, but the target may be relaxed to $<7 \%(53 \mathrm{mmol} / \mathrm{mol})$ if necessary to prevent hypoglycemia. B

\section{Preconception Counseling}

All women with diabetes who are of childbearing age should be counseled about the importance of near-normal glycemic control before conception. Observational studies show an increased risk of diabetic embryopathy, especially anencephaly, microcephaly, congenital heart disease, and caudal regression, directly proportional to elevations in $\mathrm{A} 1 \mathrm{C}$ during the first 10 weeks of pregnancy.

Preconception counseling visits should address rubella, rapid plasma regain testing, hepatitis $B$ virus, and HIV testing, as well as Pap smear, cervical cultures, blood typing, prescription of prenatal vitamins (with at least $400 \mu \mathrm{g}$ of folic acid), and smoking cessation counseling, if indicated. Diabetes-specific testing should include A1C, thyroid-stimulating hormone, creatinine, and UACR. The patient's medication list should be reviewed for potentially teratogenic drugs (e.g., ACE inhibitors or statins), and a referral should be made for a comprehensive eye exam.

\section{Postpartum Follow-up}

Because GDM may represent preexisting undiagnosed type 2 or even type 1 diabetes, women with GDM should be tested for persistent diabetes or prediabetes at 6-12 weeks postpartum with a 75-g OGTT using nonpregnancy criteria as outlined in the screening and diagnostic section on page 5. Because GDM is associated with increased maternal risk for diabetes, women should also be tested every $1-3$ years thereafter if 6 - to 12-week 75-g OGTT is normal, with 
frequency of screening depending on other risk factors, including family history, prepregnancy BMI, and need for insulin or oral glucose-lowering medication during pregnancy. Ongoing screening may be performed with any recommended glycemic test (i.e. A1C, FPG, or 75-g OGTT) with nonpregnant thresholds.

\section{DIABETES CARE IN THE HOSPITAL, NURSING HOME, AND SKILLED NURSING FACILITY}

\section{Recommendations}

- Consider performing an A1C on all patients with diabetes or hyperglycemia admitted to the hospital if one has not been performed in the previous 3 months. $\mathrm{C}$

- Insulin therapy should be initiated for treatment of persistent hyperglycemia starting at a threshold of $\geq 180 \mathrm{mg} / \mathrm{dL}(10.0 \mathrm{mmol} / \mathrm{L})$. Once insulin therapy is started, a target glucose range of 140-180 $\mathrm{mg} / \mathrm{dL}(7.8-10.0 \mathrm{mmol} / \mathrm{L})$ is recommended for the majority of critically ill patients $A$ and noncritically ill patients. C

- More stringent goals such as 110$140 \mathrm{mg} / \mathrm{dL}(6.1-7.8 \mathrm{mmol} / \mathrm{L})$ may be appropriate for selected critically ill patients, as long as this can be achieved without significant hypoglycemia. C

- Intravenous (IV) insulin infusions should be administered using validated written or computerized protocols that allow for predefined adjustments in the insulin infusion rate based on glycemic fluctuations and insulin dose. $\mathrm{E}$

- A basal plus bolus correction insulin regimen is the preferred treatment for noncritically ill patients with poor oral intake or who are taking nothing by mouth (NPO). An insulin regimen with basal, nutritional, and correction components is the preferred treatment for patients with good nutritional intake. A
- The sole use of sliding-scale insulin in the inpatient hospital setting is strongly discouraged. A

- A hypoglycemia management protocol should be adopted and implemented by each hospital or hospital system. A plan for preventing and treating hypoglycemia should be established for each patient. Episodes of hypoglycemia in the hospital should be documented in the medical record and tracked. E

- The treatment regimen should be reviewed and changed if necessary to prevent further hypoglycemia when a blood glucose value is $<70$ $\mathrm{mg} / \mathrm{dL}(3.9 \mathrm{mmol} / \mathrm{L})$. C

- There should be a structured discharge plan tailored to the individual patient. $B$

\section{Considerations on Admission}

Initial orders should state that the patient has type 1 or type 2 diabetes or no previous history of diabetes. Both hyperglycemia and hypoglycemia are associated with adverse outcomes, including death. High-quality care can often be ensured by the use of structured order sets along with quality improvement processes.

\section{Glycemic Targets in Hospitalized Patients}

\section{Standard Definition of Glucose Abnormalities}

- Hyperglycemia: $>140$ mg/dL (7.8 $\mathrm{mmol} / \mathrm{L}$ )

- Hypoglycemia : <70 mg/dL (3.9 $\mathrm{mmol} / \mathrm{L}$ )

- Severe hypoglycemia : $<40 \mathrm{mg} / \mathrm{dL}$ $(2.2 \mathrm{mmol} / \mathrm{L})$

- Admission $\mathrm{A} 1 \mathrm{C}$ value $\geq 6.5 \%$ (48 $\mathrm{mmol} / \mathrm{mol}$ ) suggests preexisting diabetes

\section{Moderate Versus Tight Glycemic Control}

Data have shown increased rates of severe hypoglycemia and mortality in tightly versus moderately controlled cohorts in critically ill patients. This evidence established new standards as noted above. Patients with a history of successful tight glycemic control in the outpatient setting who are clinically stable may be maintained with a glucose target $<140 \mathrm{mg} / \mathrm{dL}$. Conversely, higher glucose ranges may be acceptable in other appropriate patients.

\section{Antihyperglycemic Agents in Hospitalized Patients}

In most instances in the hospital setting, insulin is the preferred treatment for glycemic control.

\section{Insulin therapy}

IV insulin protocols should be used for critically ill patients. Basal-bolus regimens that include correction doses and account for oral intake may be used for many noncritical-care patients. Scheduled subcutaneous (SQ) insulin injections should align with meals and bedtime or be given every 4-6 hours if no meals are taken or if continuous enteral/parenteral therapy is being used.

SQ insulin should be administered $1-2$ hours before IV insulin is discontinued. Converting to basal insulin at $60-80 \%$ of the daily infusion dose has been shown to be effective.

Standards for Special Situations Refer to the full Standards for guidance on enteral/parenteral feedings, diabetic ketoacidosis and hyperosmolar hyperglycemic state, and glucocorticoid therapy.

\section{Perioperative Care}

On the morning of surgery or a procedure, hold any oral hypoglycemic agents; give half of the patient's NPH insulin dose or full doses of long-acting analog or pump basal insulin. Monitor blood glucose every 4-6 hours while a patient is NPO, and dose with short-acting insulin as needed with a target of $80-180 \mathrm{mg} / \mathrm{dL}$ (4.4-10.0 mmol/L).

\section{Treating and Preventing Hypoglycemia}

Standardized nurse-driven protocols should be used for hypoglycemia avoidance and treatment. Consider iatrogenic or patient factors that may result in hypoglycemia. 
Self-Management in the Hospital Diabetes self-management in the hospital may be appropriate for select youth and adult patients who successfully conduct comprehensive self-management of diabetes at home, have the cognitive and physical skills needed to successfully self-administer insulin, and perform SMBG.

\section{Medical Nutrition Therapy in the Hospital}

The goals of MNT are to optimize glycemic control, provide adequate calories to meet metabolic demands, and address personal food preferences. The term "ADA diet" is no longer used. A registered dietitian can serve as an inpatient team member.

Transition From the Acute Care Setting

Tailor a structured discharge plan beginning at admission and update as patient needs change. It is important that patients be provided with appropriate durable medical equipment, medications, supplies, and prescriptions, along with appropriate education at the time of discharge. An outpatient follow-up visit within 1 month of discharge is advised for all patients having hyperglycemia in the hospital. Continuing contact may also be needed. Clear communication with outpatient providers either directly or via structured hospital discharge summaries facilitates safe transitions to outpatient care. If oral medications are held in the hospital, there should be protocols for resuming them 1-2 days before discharge.

\section{DIABETES ADVOCACY}

Advocacy Position Statements

For a list of ADA advocacy position statements, including "Diabetes and Driving" and "Diabetes and Employment," refer to Section 14 ("Diabetes Advocacy") of the complete 2016 Standards.

\section{Acknowledgments}

This abridged version of the ADA Position Statement "Standards of Medical Care in Diabetes - 2016" was created under the guidance of Sarah Bradley (ADA staff) with invaluable expertise of ADA's Primary Care Advisory Group, with special thanks to Jay Shubrook, DO, Vallejo, CA, Primary Care Advisory Group Chair; James J. Chamberlain, MD, Salt Lake City, UT; Hope Feldman, CRNP, FNP-BC, Philadelphia, PA; Eric L. Johnson, MD, Grand Forks, ND; Sandra Leal, PharmD, MPH, FAPhA, CDE, Tucson, AZ; Andrew S. Rhinehart, MD, FACP, FACE, CDE, BC-ADM, CDTC, Abingdon, VA; Charles F. Shaefer, Jr., MD, FACP, Augusta, GA; and Neil Skolnik, MD, Jenkintown, PA. Editorial assistance was provided by Annie Neuman, MPA, PA-C, Salt Lake City, UT. 